\title{
Carreiras e Cidades: Existiria um Melhor Lugar para se Fazer Carreira?
}

\author{
Moisés Balassiano \\ Elvira Cruvinel Ferreira Ventura \\ Joaquim Rubens Fontes Filho
}

\begin{abstract}
Resumo
O objetivo do presente estudo é apresentar e discutir as principais mudanças no conceito de carreira. Duas diferentes abordagens são comparadas e contrastadas: a tradicional, com premissas voltadas eminentemente para as garantias de benefícios e segurança; e a moderna, segundo a qual o sucesso na carreira está associado à trajetória pessoal, expandindo-se o espaço de expressão para o campo pessoal, familiar e profissional, conforme Chanlat (1995), Martins (2001) e Hall (1996). De acordo com essa abordagem, surge o conceito de carreira proteana que, entre outros fatores, tem como características o aprendizado, o sucesso psicológico e a expansão da identidade, independentemente da profissão ou empresa escolhida. Assim, foi realizada uma pesquisa para identificar e ordenar as cidades, onde as dimensões dessa perspectiva de carreira se apresentam com maior intensidade. A referida pesquisa utilizou metodologia baseada em técnicas estatísticas, visando a definir e testar um conjunto de indicadores capazes de refletir as potencialidades locais, em face da teoria apresentada. Como resultado, foram ordenadas cem cidades, de acordo com critérios de inclusão, definidos para a pesquisa.
\end{abstract}

Palavras-chave: recursos humanos; gestão de pessoas; carreiras; planejamento de carreiras.

\begin{abstract}
The purpose of this study is to present and to discuss main changes in the conceptualization of career. Two different approaches are compared and contrasted: the traditional concept, based on the usual assumptions of tenure and security; and the modern view, according to which the assumption that the success, in a given career, is related to the personal trajectory, expanding itself to a more comprehensive meaning of a personal, family and professional satisfaction, as in Chanlat (1995), Martins (2001) and Hall (1996). According to the later approach, comes along the concept of protean career with learning, psychological success and the expansion of the self-identity features, regardless of profession or company that may be chosen. A research was conducted to identify and to order the cities where the dimensions of this career perspective appear with more strength. This research was based on statistical techniques methodology to define and test a set of indicators to express the local potentiality of the cities in Brazil, under the presented theory. As a result, one hundred cities were ranked according to the criterion of inclusion defined for the study.
\end{abstract}

Key words: human resources; people managing; careers; career planning. 


\title{
INTRODUÇÃO
}

\author{
Career: Old meaning: a course of professional \\ advancement; usage restricted to occupations with formal \\ hierarchical progression, such as managers and \\ professionals. New meaning: the unfolding sequence of any \\ person's work experiences over time. \\ Arthur e Rousseau, 1996, p.28
}

As mudanças no ambiente organizacional têm sido apontadas como geradoras de inúmeras transformações nas práticas administrativas. O mesmo ocorre com a idéia de carreira. Numa perspectiva temporal, verifica-se um deslocamento da concepção de carreira voltada para a empresa (por exemplo: funcionário dos Correios, do Banco do Brasil, da Xerox etc.), para uma concepção mais moderna, individualizada, em que as pessoas são preparadas a assumir as decisões sobre seu próprio destino. No interregno entre esses dois momentos, registra-se a carreira focada nas profissões (médico, engenheiro etc.).

Obviamente, tais mudanças não ocorreram repentinamente. Até hoje, são encontrados ambientes organizacionais onde prevalece uma ou outra perspectiva. Não obstante, algumas práticas prevalecem no momento da escolha - quando possível -do melhor lugar para se fazer carreira. Este artigo apresenta uma perspectiva histórica das principais mudanças no conceito de carreira e um estudo para identificar, listar e ordenar cidades que apresentem condições para o desenvolvimento das pessoas, de acordo com a visão moderna de carreira.

\section{A Evolução do Conceito de Carreira}

Segundo Martins (2001), etimologicamente a palavra carreira se origina do latim medieval via carraria, que significa estrada rústica para carros. Mas o conceito de carreira, tal qual o conhecemos hoje, como trajetória da vida profissional, é recente, tendo aparecido no século XIX. A palavra quer dizer "um ofício, uma profissão que apresenta etapas, uma progressão” (Chanlat, 1995, p. 69).

O conceito de carreira pode ser dividido em duas fases distintas: um conceito tradicional e um conceito moderno, com uma ruptura que se dá a partir dos anos 1970. 
Na abordagem tradicional, ainda encontrada em alguns países, regiões ou empresas, a carreira é preponderantemente feita por um homem pertencente aos grupos socialmente dominantes. É marcada por relativa estabilidade e, progressão linear vertical; e existe certa estabilidade no emprego (Chanlat, 1995, p. 72). Essa abordagem era consoante ao tipo de sociedade masculina e de certa estabilidade, comum até os anos 1970.

Nessa perspectiva tradicional, há uma mentalidade de que os benefícios são direitos assegurados e de que as organizações empregadoras devem assumir a responsabilidade pelas carreiras de seus empregados. Em síntese, a carreira é da empresa, pois é ela que permite os acessos e gerencia o desenvolvimento. E o sucesso na carreira tradicional pode ser medido pelo quão alto se chegou na hierarquia da organização.

Chanlat (1995, p.72) tipifica o modelo moderno de carreira em quatro grandes tipos:

\section{Quadro 1: Tipos de Carreiras}

\begin{tabular}{|c|c|c|c|c|c|}
\hline $\begin{array}{l}\text { Tipos de } \\
\text { carreira }\end{array}$ & $\begin{array}{l}\text { Recursos } \\
\text { principais }\end{array}$ & $\begin{array}{l}\text { Elemento } \\
\text { central de } \\
\text { ascensão }\end{array}$ & $\begin{array}{l}\text { Tipos de } \\
\text { organização }\end{array}$ & Limites & $\begin{array}{l}\text { Tipos de } \\
\text { sociedades }\end{array}$ \\
\hline Burocrática & $\begin{array}{c}\text { Posição } \\
\text { hierárquica }\end{array}$ & $\begin{array}{c}\text { Avanço de uma } \\
\text { posição } \\
\text { hierárquica a } \\
\text { outra }\end{array}$ & $\begin{array}{l}\text { Organizações } \\
\text { de grande porte }\end{array}$ & $\begin{array}{l}\text { Número de } \\
\text { escalões } \\
\text { existentes }\end{array}$ & $\begin{array}{l}\text { Sociedade de } \\
\text { empregados }\end{array}$ \\
\hline Profissional & $\begin{array}{l}\text { Saber e } \\
\text { reputação }\end{array}$ & $\begin{array}{l}\text { Profissão } \\
\text { Perícia } \\
\text { Habilidades } \\
\text { profissionais }\end{array}$ & $\begin{array}{c}\text { Organização de } \\
\text { peritos } \\
\text { Burocracia } \\
\text { Profissional }\end{array}$ & $\begin{array}{l}\text { Nível de } \\
\text { perícia e } \\
\text { reparação }\end{array}$ & $\begin{array}{l}\text { Sociedade de } \\
\text { peritos }\end{array}$ \\
\hline \multirow[t]{2}{*}{ Empreendedora } & $\begin{array}{l}\text { Capacidade } \\
\text { de criação } \\
\text { Inovação }\end{array}$ & \multirow{2}{*}{$\begin{array}{c}\text { Criação de } \\
\text { novos valores, } \\
\text { novos produtos } \\
\text { e serviços }\end{array}$} & $\begin{array}{l}\text { Pequenas e } \\
\text { médias } \\
\text { empresas }\end{array}$ & $\begin{array}{l}\text { Capacidade } \\
\text { pessoal }\end{array}$ & \multirow{2}{*}{$\begin{array}{c}\text { Sociedade que } \\
\text { valoriza a } \\
\text { iniciativa } \\
\text { individual }\end{array}$} \\
\hline & & & $\begin{array}{c}\text { Empresas } \\
\text { artesanais, } \\
\text { culturais, } \\
\text { comunitárias e } \\
\text { de caridade }\end{array}$ & $\begin{array}{c}\text { Exigências } \\
\text { externas }\end{array}$ & \\
\hline Sociopolítica & $\begin{array}{l}\text { Habilidades } \\
\text { sociais } \\
\text { Capital de } \\
\text { relações }\end{array}$ & $\begin{array}{c}\text { Conhecimento } \\
\text { Relações de } \\
\text { parentesco } \\
\text { Rede social }\end{array}$ & $\begin{array}{c}\text { Familiar } \\
\text { Comunitária de } \\
\text { clãs }\end{array}$ & $\begin{array}{l}\text { Número de } \\
\text { relações } \\
\text { conhecidas e } \\
\text { ativas }\end{array}$ & $\begin{array}{l}\text { Sociedade de } \\
\text { clãs }\end{array}$ \\
\hline
\end{tabular}

Fonte: Chanlat (1995, p.72).

A abordagem moderna de carreira surge em decorrência de mudanças sociais, tais como a feminização do mercado de trabalho, a elevação dos graus de instrução, 
a cosmopolização do tecido social, a afirmação dos direitos dos indivíduos, a globalização da economia e a flexibilização do trabalho, entre outros (Chanlat, 1995, p. 72). Assim, nessa abordagem não importa o sexo ou a origem social do indivíduo, pois todos podem fazer carreira.

Apesar de mais democrático, o moderno modelo de carreira se caracteriza pela instabilidade, descontinuidade e horizontalidade, em contraposição ao modelo tradicional. Essa mudança necessariamente não significou progresso e bem-estar para as pessoas, que se tornam as responsáveis por suas próprias carreiras. Tal tipificação do modelo moderno de carreira dá conta dos diversos tipos coexistentes de profissionais no mercado, o que vai depender das características da função e da organização a que está vinculado. Assim, em organizações de grande porte ainda persiste a carreira do tipo burocrático, muito embora haja tendência de que essas organizações flexibilizem cada dia mais suas estruturas e a forma de ascensão, passando a valorizar atributos próprios de outros tipos de carreira, como o saber, a criatividade e o capital de relações, por exemplo. Assim, mesmo em grandes e tradicionais empresas, incluindo as do setor público, pouco a pouco, a mentalidade e as atitudes estão se reconfigurando ao novo conceito de carreira, em que a capacidade de inovar e flexibilizar são fatores-chaves.

Importa salientar que ainda existem profissionais que sonham com a possibilidade de fazer carreira nos moldes do conceito tradicional, em que as responsabilidades por seu desenvolvimento são muito mais da própria empresa que do indivíduo. Assim, o novo conceito de carreira envolve mudança no contrato psicológico entre os participantes, principalmente no quesito lealdade empregadoempresa. A questão que se coloca é: como buscar a dedicação de um profissional, se não se pode oferecer a garantia de emprego? Brown (1996) trabalha essa questão em sua pesquisa, mostrando como os empregados de uma empresa identificavam, de forma irônica, as características desse novo contrato, segundo o ponto de vista dos empregadores:

Não podemos prometer quanto tempo vamos ficar nesse negócio.

Não podemos prometer que não vamos ser adquiridos.

Não podemos prometer que haverá espaço para promoções.

Não podemos prometer que seu emprego continuará existindo, quando você atingir a idade de se aposentar.

Não podemos prometer que o dinheiro estará disponível para sua pensão.

Não podemos esperar por sua eterna lealdade, e não estamos certos que queremos isso (Brown, 1996, p. 24) 
Nesse novo contrato, a responsabilidade da empresa pela carreira do empregado é quase nula. Nos novos termos, quem assume grande parte dos riscos é o empregado, liberando a empresa para seus processos de flexibilização.

Similarmente ao conceito moderno de carreira descrito por Chanlat, Hall (1996) apresenta o conceito de carreira proteana, entendida como uma série de experiências e de aprendizados pessoais, relacionados com trabalho ao longo da vida. Seria também um contraponto à carreira tradicional, estruturada no tempo e no espaço. Segundo Hall (1996), a carreira no século XXI será predominantemente proteana, dirigida pelas pessoas, não pelas organizações, e reinventada de tempos em tempos. A denominação proteana deriva do deus grego Proteus que, segundo a mitologia, possuía a habilidade de mudar de forma ao comando de sua vontade. Para o autor, o mito de Proteus revela elementos que podem ser metaforicamente observados no profissional contemporâneo que tem a habilidade de gerenciar sua própria carreira.

Ao propor essa mudança na visão de carreira, Hall (1996, p. 8) argumenta que o principal objetivo de uma carreira éo sucesso psicológico do indivíduo, um sentimento de orgulho e realização pessoal, por alcançar seus objetivos de vida, felicidade familiar, paz interior, dentre outros, em contraposição à perspectiva tradicional de sucesso que buscava a escalada dos níveis hierárquicos em uma organização.

\section{Proteana: Novo Conceito de Carreira}

O antigo contrato de emprego tinha como características que o sustentavam a administração paternalista, lealdade associada ao desenvolvimento de uma carreira de longo prazo na organização e a recompensa pelo desempenho, substantivada na promoção (Burke, 1998). O novo contexto do ambiente operativo das empresas torna a manutenção desse modelo de contrato insuficiente para lidar com as novas nuanças do mercado e das aspirações de indivíduos e organizações.

A abordagem de carreira proteana apresenta nova proposta. Considera que existem três espaços de expressão do indivíduo: o pessoal, o familiar e o profissional. Para Hall (1996a), em cada um desses espaços o indivíduo apresenta várias subidentidades que desempenham diferentes papéis. A identidade é o autoconceito de um indivíduo, a percepção e a avaliação que tem de si mesmo. Para os autores, a carreira proteana é formada por uma sucessão de miniestágios, ou pequenos ciclos, de exploração-tentativa-domínio-saída, à medida que o trabalhador entre e saia de áreas, organizações ou funções. Essa forma de carreira envolve, ainda, o crescimento horizontal, para expansão das competências e estabelecimento de novos relacionamentos com trabalhos e outras pessoas. Seu objetivo final é o aprendizado, o sucesso psicológico e a expansão da identidade. Como contrapõem, 
"in the more traditional form, the goal was advancement, success and esteem in the eyes of others, and power" (Hall, 1996, p.35).

De acordo com Hall (1996), o novo contrato de carreira para o século XXI encontra-se apoiado nas características de sucesso psicológico, aprendizagem contínua, novas fontes de desenvolvimento e novo perfil de sucesso.

O sucesso psicológico é representado pelo alcance de um conjunto de expectativas mútuas implícitas entre empregadores e empregados, enfocado nas contribuições de ambas as partes. Ao contrário do modelo relacional, baseado em relacionamento de comprometimento e confiança duradouro, o novo contrato é transacional, apoiado em trocas de curto prazo por benefícios e serviços (Hall,1996a). O contrato psicológico, na visão proteana, deixa de ser aquele realizado com a organização, mas o que o indivíduo realiza consigo mesmo, de modo que o critério de sucesso se torna algo interno. Similarmente aos modelos estudados pela teoria da agência, o novo contrato psicológico tem uma natureza outcome-based, e não behaviour-based.

Pelo conceito da aprendizagem contínua, o novo modelo de carreira deixa de ser mensurado pela idade cronológica e pelas etapas da vida, mas pelo contínuo aprendizado e mudança de identidade. As fontes de desenvolvimento passam a ser os desafios no trabalho e os relacionamentos. Treinamentos formais tornamse menos relevantes que o aprendizado alcançado na realização de trabalhos estimulantes e desafiadores. Nesse contexto, o novo perfil de sucesso deixa de ser o know-how e passa a ser o learn-how. As habilidades pessoais se fundem dentro do ambiente de trabalho, resgatando a visão integral do indivíduo e permitindo que mais energia criativa seja trazida ao trabalho.

O quadro seguinte apresenta as características da carreira proteana no século XXI:

\section{Quadro 2: Características da Carreira Proteana}

\begin{tabular}{l}
\hline Objetivo: sucesso psicológico \\
\hline Carreira: administrada pelo indivíduo, não pela organização \\
\hline Carreira: estende-se por toda a vida como uma série de mudanças de identidade e aprendizado \\
contínuo \\
\hline O que conta: é a idade da carreira, e não a idade cronológica \\
\hline Organização: provê trabalhos desafiadores e relacionamentos \\
\hline Desenvolvimento: não é necessariamente treinamento formal, readaptação, mobilidade vertical \\
\hline Perfil de sucesso: \\
- Do know-how para o learn-how \\
- Da segurança no trabalho para a empregabilidade \\
- Das carreiras organizacionais para as carreiras proteanas \\
\hline
\end{tabular}

Fonte: Hall (1996, p. 9). 
A existência de duas vertentes para o conceito de carreira, a tradicional e outra não baseada nas mesmas premissas, também pode ser associada ao estilo de benefício esperado pelos profissionais a elas associados. Blau e Tatum (2002) propõem a discussão sobre carreira em associação à satisfação com os benefícios recebidos. Questionam se o trabalhador associado a uma carreira proteana valoriza os mesmos benefícios oferecidos pela carreira tradicional, tais como segurança e benefícios de seguridade, ou se irão privilegiar o potencial de desenvolvimento (career enrichment). Os estudos que realizaram com um grupo de tecnologistas médicos permitiram validar a hipótese de dois modelos de benefícios, o básico e de enriquecimento de carreira, atuando paralelamente às carreiras tradicional e proteana.

A carreira proteana assume e acomoda duas tendências sociais importantes, que estão provocando reorganizações no ambiente de trabalho, conforme apontadas por Evans (1996). A primeira delas é a mudança de "uma ética de trabalho baseada em dever, para uma baseada em hedonismo, ou prazer” (Evans, 1996, p. 15). Se antes o trabalho era percebido como dever para com a família e a empresa, seu significado passa a incorporar mais fortemente elementos de divertimento e eficiência.

A segunda tendência social marcante é a autonomia, a necessidade percebida pelos indivíduos de independência. Significa a busca pelo controle da própria vida e a negação ao poder impessoal da autoridade. Convergente à proposta da carreira proteana, Evans (1996) afirma que as carreiras estão se tornando de natureza espiral, ziguezagueando em vez de seguirem uma escada.

\section{Críticas ao Novo Conceito de Carreira}

Em que pese o entusiasmo de diversos autores em torno da visão de carreira como inerente ao indivíduo, há também aqueles que divergem e apontam seus possíveis prejuízos, principalmente para as organizações.

“... if employees are to be discouraged from staking any significant portion of their careers with any one organization, who will care enough to drive organizations forward, toward growth and prosperity? With no special ties to, or identity with, the organization, employees may not even have enough of an emotional stake in longterm organizational outcomes to feel alienated from their employers. Indifference and opportunistic apathy could become widespread" (Brousseau, 1996, p. 55). 
Também entre os empregados não é homogênea a adesão a essa nova visão de carreira. A partir de pesquisa entre os graduados em uma escola de negócios canadense, Burke (1998) identificou que tanto indivíduos quanto organizações se encontravam em processo de transição. A partir das análises, propõe como hipótese que a nova forma de relacionamento de trabalho irá combinar ambos os modelos de carreira, novo e antigo, para alguns empregados ou em algumas organizações.

Inseguras com a novidade e pressionadas por seus empregados, as organizações podem ser levadas a adotar novos modelos de carreira e de relacionamento com seus empregados (ou ex-empregados). Como alertam Brousseau (1996), essas mudanças podem levar as organizações e seus líderes a se perceberem liberados de responsabilidades pela carreira de seus empregados, embora estes possam continuar a necessitar tanto de mudança quanto de estabilidade. Precisam estar preparados para se governarem, sem contar com mais ninguém ou nada, exceto suas próprias capacidades (Brousseau, 1996, p. 54).

Para os indivíduos, essas mudanças podem também ser bastante traumáticas. Nicholson (1996) discute o impacto psicológico sobre os empregados e apresenta análises, um tanto céticas, quanto à capacidade de os novos modelos de carreira organizacionais abolirem estruturas hierárquicas ou virtuais de trabalho. Apoiandose na psicologia evolucionária afirma que "we not only require opportunities to interact and display to each other, but we also seem genetically addicted to hierarchy” (Nicholson, 1996, p. 50). O psicanalista Jurandir Freire Costa estabelece um paralelo entre o novo regime de trabalho e a diluição do vínculo vitalício com um emprego e uma crise afetiva que se intensifica na sociedade, provocada pela fragmentação dos projetos individuais (Cezimbra, 2003, p. 1).

\section{Carreiras e Cidades: Existiria um Melhor lugar para se Fazer CARREIRA?}

A discussão anterior aponta a tendência da diferenciação do conceito de carreira como associado unicamente a uma organização, o que provoca a reflexão sobre a existência de parâmetros que permitam delinear condições de contorno que estimulariam seu desenvolvimento.

Uma vez que a carreira passa a ser vista como contrato psicológico mais abrangente, definido por um conjunto mais amplo de aspirações individuais, tais como condições para o desenvolvimento, busca de novos desafios, aprendizagem e relacionamentos, o locus da carreira se transfere da organização para o meio. Não adianta apenas trabalhar em empresa com boa política de pessoal, segundo 
as premissas do modelo tradicional de carreira, se não há espaço para o fortalecimento de uma visão integral do indivíduo.

A visão de carreira proteana exige que o ambiente empresarial e social ofereça condições para seu florescimento, de modo a permitir tanto o desenvolvimento profissional quanto o pessoal. Para Martins (2001), ao lado do auto-conhecimento, o conhecimento do ambiente de carreiras é mais um aspecto fundamental para a gestão da carreira proteana com foco no sucesso psicológico. Dessa forma, podemos identificar o lugar de trabalho - a cidade - como elemento fundamental na escolha de uma carreira. Esse conhecimento não é estático, mas processual. O profissional deve buscar constantemente atualizar-se sobre esses elementos, para melhor gerir sua carreira.

Nesse sentido, foi conduzida uma investigação que visa identificar e testar um conjunto de indicadores que permitam avaliar o potencial de determinadas cidades para gerar as condições do desenvolvimento pessoal e profissional de seus indivíduos, no sentido proteano, isto é, contemplando a dimensão pessoal, familiar e profissional. A inexistência de experiência similar fez desta investigação um trabalho pioneiro no campo da administração. O desenho metodológico é explicitado mais adiante, a fim de permitir, com sua disseminação, um aprofundamento das discussões acerca das bases teóricas subjacentes ao campo.

\section{Aspectos Metodológicos}

Definidas as bases conceptuais, detalhadas na sessão anterior, passou-se à definição dos critérios de inclusão das unidades observacionais, ou seja, as cidades, bem como as variáveis que poderiam servir de indicadores do objeto de investigação. Inicialmente, foram estabelecidos dois critérios para a inclusão das cidades no escopo do trabalho: a) população residente superior a 170.000 habitantes; e b) depósitos bancários a vista superiores a R $\$ 210$ milhões, ambos com data-base em 2000. Esses valores representam o $95^{\circ}$ percentil das respectivas distribuições, e foram observados simultaneamente. Desse modo, as cidades participantes representam as $5 \%$ mais populosas e com maiores depósitos bancários a vista. De acordo com esse critério, 103 cidades foram inicialmente incluídas no estudo.

Posteriormente, foram incorporadas outras seis cidades, em função das suas potencialidades não enquadradas nos critérios previamente estabelecidos. Estas cidades são: Macaé (RJ), Cubatão (SP), Rio Claro (SP), São Caetano do Sul (SP), Itajaí (SC) e Bento Gonçalves (RS).

Na definição dos indicadores de potencialidades de carreiras, partiu-se de um 
elenco inicial de 36 variáveis socioeconômico-demográficas que retratavam as dimensões proteanas anteriormente descritas. Os critérios de escolha dessas variáveis foram pautados na hipótese de que os espaços pessoais, familiares e profissionais estão relacionados com a vitalidade e infra-estrutura oferecidas pelos municípios a seus habitantes. Sendo assim, a vitalidade deveria ser avaliada de acordo com a capacidade do município gerar recursos, através de impostos, bem como dos fatores relacionados com o capital e trabalho, enquanto a infra-estrutura contemplaria a oferta de educação, serviços de saúde, moradia e demais serviços.

Esses indicadores foram submetidos a uma análise fatorial exploratória, visando determinar a dimensionalidade subjacente a esse conjunto, a partir das associações entre eles, bem como identificar os indicadores mais relevantes na constituição das dimensões. Foram, então identificadas cinco dimensões e 20 indicadores significativos e com significação teórica. Na determinação da dimensionalidade do espaço, a análise fatorial forneceu o gráfico do scree plot, apresentado na Figura 1. De acordo com Johnson e Wichern (2002), o número de dimensões a serem extraídas deve ser o indicado pelo "cotovelo" da curva. O procedimento estatístico foi realizado por meio do programa SPSS, na versão 11.5.

Por meio da Figura 1, nota-se que o número de componentes, pelo método heurístico do "cotovelo", recai entre quatro e cinco, indicando o melhor número de fatores para explicar as associações entre as variáveis. Uma análise do grupamento dos indicadores em quatro componentes revelou certas inconsistências quanto à classificação de alguns desses indicadores, enquanto a de cinco componentes separou o elenco de indicadores em grupamentos com maior sentido lógico.

\section{Figura 1: Dimensionalidade dos Dados}

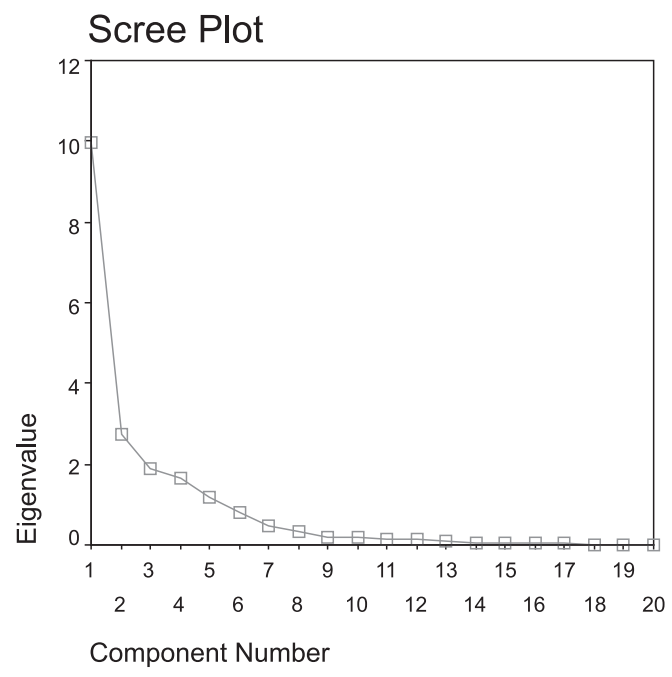


Com essa dimensionalidade, obedeceu-se à alocação dos indicadores pelos cinco fatores definidos pelo procedimento. Baseada nesta alocação foi determinada a melhor taxionomia para expressar cada fator em função do que os indicadores representavam em comum.

O Quadro 3 apresenta o percentual da variação total, explicada por cada um dos fatores extraídos. Nota-se que a retenção de quatro fatores levaria a uma explicação total das variações dos indicadores à ordem de $78 \%$, enquanto a retenção de cinco fatores levou a $87 \%$ de explicação, ou seja, verificou-se um incremento de $9 \%$ na explicação da variação total dos 20 indicadores.

\section{Quadro 3: Variância Total Explicada por Cada Componente e Acumulada}

\begin{tabular}{cccc}
\hline Componente & Total & $\begin{array}{c}\text { \% de } \\
\text { Variação }\end{array}$ & \% Cumulativo \\
\hline 1 & 5,158 & 25,79 & 25,79 \\
\hline 2 & 4,673 & 23,37 & 49,16 \\
\hline 3 & 3,063 & 15,31 & 64,47 \\
\hline 4 & 2,720 & 13,60 & 78,07 \\
\hline 5 & 1,850 & 9,25 & 87,32 \\
\hline
\end{tabular}

O Quadro 4 apresenta a distribuição dos indicadores por fator, bem como a taxionomia deles e as cargas fatoriais. Considerando que as cargas fatoriais devem variar, em valor absoluto, entre 0,0 e 1,0, e que quanto maior seu valor maior a validade do indicador na conceptualização do fator, nota-se elevado grau de ajustamento de cada indicador na determinação de todos os fatores. Além disso, de modo geral, os resultados alcançados representam uma situação lógica e esperada previamente. Apenas dois fatores - impulsionador e dinamismo - tiveram que ser classificados em função de seus conteúdos, ao passo que os demais retrataram basicamente o que os indicadores já manifestavam a priori, isto é, educação, saúde e impostos. Embora um indicador deva medir apenas um construto, de modo a evitar ambigüidades, nada impede, na teoria (McDonald, R. - comunicação pessoal), que essa regra seja violada. $\mathrm{O}$ indicador que representa o número de pessoas com carteira de trabalho ocupadas per capta, PTOTPCT, mostrou-se fidedigno na mensuração dos fatores Impulsionador e Dinamismo. 


\section{Quadro 4: Cargas Fatoriais dos Indicadores por Fator (após Rotação dos Fatores)}

\begin{tabular}{|c|c|c|c|c|c|}
\hline & & & mponer & & \\
\hline & 1 & 2 & 3 & 4 & 5 \\
\hline CURSGRAD & 0,900 & & & & \\
\hline MATRICUL & 0,899 & & & & \\
\hline CONCLUIN & 0,898 & & & & \\
\hline CURMESTR & 0,831 & & & & \\
\hline CURDOUTR & 0,846 & & & & \\
\hline DEPOPCTA & & 0,800 & & & \\
\hline APLIPCTA & & 0,587 & & & \\
\hline PCARTPCT & & 0,835 & & & \\
\hline PTOTPCT & & 0,753 & 0,523 & & \\
\hline AGENCPCT & & & 0,758 & & \\
\hline DOMICPCT & & & 0,898 & & \\
\hline EMPCGCPC & & & 0,887 & & \\
\hline MLEITPCT & & & & 0,934 & \\
\hline MHOSPCT & & & & 0,945 & \\
\hline LNICMSPC & & & & & 0,894 \\
\hline LNISSPCT & & & & & 0,838 \\
\hline LNITBIPC & & & & & 0,860 \\
\hline LNIPTUPC & & & & & 0,769 \\
\hline LNIPVAPC & & & & & 0,877 \\
\hline LNIRRFPC & & & & & 0,882 \\
\hline
\end{tabular}

Método de extração: componentes principais -método de rotação: varimax.

O primeiro componente foi classificado como "fator educação", formado pelos seguintes indicadores:

. número de cursos de graduação, CURSGRAD;

. número de matrículas nos cursos de graduação, MATRICUL;

. número de concluintes nos cursos de graduação, CONCLUIN;

. número de cursos de mestrado, CURMESTR;

. número de cursos de doutorado, CURDOUTR.

O segundo componente foi classificado como "fator impulsionador", ou "ativador de carreiras”, em função do conteúdo de seus indicadores:

. volume de depósito por agência per capta, DEPOPCTA;

. volume de aplicações financeiras por agência per capta, APLIPCTA;

. trabalhadores com carteira assinada, PCARTPCT;

. pessoal total ocupado, РTOTPCT. 
Classificou-se o terceiro componente como "fator dinamismo", apresentado pelas cidades em face dos indicadores nele incorporados. Esse fator expressa os diferentes elementos estruturais associados às cidades pesquisadas. Os indicadores desse fator foram:

. número de agências bancárias, AGENCPCT;

. número de domicílios, DOMICPCT;

. número de empresas com CNPJ atuantes, EMPCGCPC;

. pessoal total ocupado, PTOTPCT.

O quarto fator expressa a oferta de serviços de saúde das cidades. Os indicadores associados ao "fator saúde" foram: o número de leitos por mil habitantes, MLEITPCT, e o número de unidades hospitalares por mil habitantes, MHOSPCT. A escolha desses indicadores se justifica pela importância que tais serviços desempenham nas cidades que agregam maior capacidade econômica.

Finalmente, o quinto fator foi definido pelos diferentes impostos e taxas cobradas nos três níveis de governo. A premissa básica do "fator impostos” é a de que cidades com maior capacidade de gerarem impostos são aquelas em que a atividade econômica é mais intensa. Os indicadores considerados foram:

. Imposto de Renda Retido na Fonte, LNIRRFPC;

. Imposto de Circulação de Mercadorias, LNICMSPC;

. Imposto Predial e Territorial Urbano, LNIPTUPC;

. Imposto sobre Serviços, LNISSPCT;

. Imposto de Transmissão de Bens Imobiliários, LNITBIPC;

. Imposto sobre a Propriedade de Veículos Automotores, LNIPVAPC.

Os dados sobre Educação foram obtidos do Instituto Nacional de Estudos e Pesquisas Educacionais Anísio Teixeira, INEP, relativos ao ano de 2000, e da Coordenação de Aperfeiçoamento de Pessoal de Nível Superior, CAPES, de 2000. Os dados relativos às variáveis dos fatores Impulsionador, Dinamismo e Saúde foram fornecidos pelo Censo de 2000 do Instituto Brasileiro de Geografia e Estatística. Os dados sobre arrecadação foram fornecidos pela Secretaria do Tesouro Nacional, STN, relativos a 2000.

Com base nos indicadores, foi obtida a pontuação para cada fator. Essa 
pontuação foi reescalonada para ter média 100 e desvio padrão 20; assim, todos os fatores estariam na mesma escala, permitindo possíveis comparações. Mais adiante, foi obtida a pontuação final das cidades, média ponderada das pontuações dimensionais, onde cada fator recebeu peso relativo ad hoc, de acordo com sua importância relativa no contexto geral, conforme se explicita a seguir.

\section{Quadro 5: Ponderação dos Fatores}

\begin{tabular}{lc}
\hline \multicolumn{1}{c}{ Fator } & Peso \\
\hline Educação & 5 \\
\hline Impulsionador & 4 \\
\hline Dinamismo & 3 \\
\hline Saúde & 2 \\
\hline Impostos & 1 \\
\hline
\end{tabular}

A pontuação final permitiu a ordenação decrescente das cidades, de acordo com a tabela constante do Anexo 1. Nota-se que, com exceção de Niterói, todas as cidades nas 10 primeiras posições, eram capitais estaduais, sem qualquer resultado não esperado entre eles.

Dentre as cidades mais bem colocadas, Santos (SP) foi a única surpresa, na $14^{a}$. posição. Não obstante, uma verificação nos indicadores considerados confirma efetivamente o que foi objeto de avaliação, ou seja, a potencialidade da cidade em propiciar as condições favoráveis ao desenvolvimento de carreiras, no sentido proteano.

Do ponto de vista metodológico, deve-se destacar o alto grau de consistência interna dos indicadores, expresso pelas correlações entre os indicadores dentro de cada componente, bem como pelo coeficiente alpha padronizado (Cronbach, 1947), calculado para cada fator conforme abaixo.

\section{Quadro 6: Coeficiente Alpha Padronizado}

\begin{tabular}{lc}
\hline \multicolumn{1}{c}{ Fator } & Std Alpha \\
\hline Educação & 0,9689 \\
\hline Impulsionador & 0,8902 \\
\hline Dinamismo & 0,8974 \\
\hline Saúde & 0,8824 \\
\hline Impostos & 0,9343 \\
\hline
\end{tabular}




\section{Comentários Finais}

Este artigo buscou direcionar um novo problema que surge para os indivíduos em suas trajetórias profissionais, qual seja, como construir sua carreira. Anteriormente, tal problema se solucionava pela inserção em grande empresa, que lhe proporcionaria desenvolvimento, remuneração, segurança e, não menos importante, a sensação de pertencer a uma comunidade. A nova dinâmica empresarial, com elevada rotatividade do pessoal, terceirização e redução dos níveis hierárquicos, tornou difícil a manutenção daquele modelo. A carreira deixou de ser responsabilidade da empresa e tornou-se problema de cada indivíduo.

Nesse sentido, a proposta de carreira proteana apresenta-se como forma de compreender essa nova trajetória profissional, ao propor um conceito de carreira vinculado às expectativas individuais, formado pelo espaço pessoal, profissional e familiar. A questão “onde fazer carreira”, não mais pode ser respondida por uma lista de empresas, mas pelo contexto geográfico que permita otimizar as expectativas mais amplas, tanto de desenvolvimento profissional, formação e remuneração, quanto de qualidade de vida. A resposta à questão desloca-se, portanto, das empresas para as cidades.

Neste trabalho as dimensões propostas pela carreira proteana foram associadas a variáveis relacionadas às características das cidades que possam servir de atração de indivíduos. A partir do agrupamento dessas variáveis ambientais em fatores, foram atribuídos pesos a esses fatores, o que permitiu desenvolver a classificação das cidades segundo uma escala que refletisse as melhores condições para o desenvolvimento de carreiras na perspectiva proteana. Os melhores lugares para se fazer carreira são, portanto, associados às cidades que apresentam melhor estrutura para o dinamismo econômico, condições para desenvolvimento em educação superior, atividade econômica, condições da rede saúde, e capacidades associadas ao impulso das carreiras, em especial aquelas do trabalho formal.

Como todo o novo conceito administrativo, as idéias recentes sobre carreira tendem a estar associadas a uma imagem de modernidade, na qual o empreendedorismo e o desenvolvimento integral do ser humano emergem como dimensões basilares. A busca pelo permanente desenvolvimento, pela independência profissional e financeira, e a união da vida profissional e pessoal é certamente um "canto de sereia", com poder de aglutinar interessados em torno da idéia.

Ainda assim, o crescimento de novo modelo de carreira, impulsionado pelas mudanças no contexto empresarial, de amplitude competitiva global, representa a desvalorização do modelo tradicional, em torno do qual a grande maioria dos 
indivíduos construía sua vida profissional e pessoal. É provável que esse e outros novos modelos venham a coexistir com modelos tradicionais, aumentando o espaço para comparações, e eventuais decepções e medo de mudanças.

\section{Artigo recebido em 10.11.2003. Aprovado em 05.02.2004.}

\section{ReferênCias Biblográficas}

ARTHUR, M. B.;

ROUSSEAU, D. M.

A career lexicon for the $21^{\text {st }}$ century. Academy of Management Executive, v.10, n.4, p.28-39, Nov. 1996.

\section{BLAU, G;}

TATUM, D. S.

Further distinguishing basic versus career enrichment: benefit satisfaction. Benefits Quarterly, p.27-34, third quarter 2002.

\section{BROUSSEAU, K. R., et al.}

Career pandemonium: realigning organizations and individuals. Academy of Management Executive, v.10, n.4, p.52-66, Nov.1996.

\section{BROWN, T.}

Pursuing the protean employee. Management Review, v.85, n.9, p.2425, Sept. 1996.

\section{BURKE, R. J.}

Changing career rules: clinging to the past or accepting the new reality? Career Development International, v.3, n.1, p.40-45, 1998.

\section{CEZIMBRA, M.}

Prontidão afetiva: psicanalistas dizem que a busca obsessiva por boa forma, sensualidade, beleza e juventude não traz felicidade. O Globo, 6 abr. 2003. Caderno Jornal da Família, p.12 .

CHANLAT, J. F.

Quais carreiras e para qual sociedade? (I). Revista de Administração de Empresas. São Paulo, v.35, n.6, p.6775, 1995.

Quais carreiras e para qual sociedade? (II). Revista de Administração de Empresas. São Paulo, v.36, n.1, p.1320, 1996.

\section{CRONBACH, L. J.}

Test reliability: Its meaning and determination. Psychometrika, v. 12, n. 1, p. 1-16, 1947.

EVANS, $P$.

Carreira, sucesso e qualidade de vida. Revista de Administração de Empresas, v. 36, n.3, p.14-22, jul./ago./set. 1996.

GREENHAUS, J. H., et al.

Career management. 3. ed. Orlando: Harcourt Inc., 2000.

HALL, D. T.

Protean careers of the $21^{\text {st }}$ century. Academy of Management Executive, v.10, n.4, p.8-16, Nov. 1996. 
HALL, D. T., et al.

The career is dead, long live the career: a relational approach to careers. San Francisco: Jossey-Bass Inc., 1996a.

JOHNSON, R. A;

WICHERN, D. W.

Applied multivariate statistical analysis. Fifth Edition. New Jersey: Prentice Hall. 2002.

MARTINS, H. T.

Gestão de carreiras na era do conhecimento: abordagem conceitual e resultados de pesquisa. Rio de Janeiro: Qualitymark, 2001.

\section{NICHOLSON, $\mathrm{N}$.}

Career systems in crisis: change and opportunity in the information age. Academy of Management Executive, v.10, n.4, p. 40-51, Nov. 1996.

SCHEIN, E. H.

Career dynamics: matching individual and organizational needs. Addison-Wesley Publishing Company, 1978. 
Anexo 1: Ranking das 100 Melhores Cidades para se Fazer Carreira-2001

\begin{tabular}{|c|c|c|c|c|c|}
\hline São Paulo & 143,6 & 01 & Araraquara & 98,7 & 51 \\
\hline Rio de Janeiro & 138,5 & 02 & Duque de Caxias & 98,4 & 52 \\
\hline Belo Horizonte & 122,5 & 03 & Piracicaba & 98,1 & 53 \\
\hline Porto Alegre & 118,3 & 04 & Osasco & 98,0 & 54 \\
\hline Curitiba & 118,2 & 05 & Volta Redonda & 97,8 & 55 \\
\hline Recife & 117,8 & 06 & São José dos Pinhais & 97,7 & 56 \\
\hline Goiânia & 117,5 & 07 & Joinville & 97,2 & 57 \\
\hline Niterói & 115,4 & 08 & Americana & 97,2 & 58 \\
\hline Brasília & 113,6 & 09 & Campos & 96,9 & 59 \\
\hline Vitória & 112,2 & 10 & Contagem & 96,8 & 60 \\
\hline Salvador & 110,9 & 11 & Ponta Grossa & 96,7 & 61 \\
\hline Campinas & 110,8 & 12 & São Gonçalo & 96,6 & 62 \\
\hline Fortaleza & 110,2 & 13 & Pelotas & 96,6 & 63 \\
\hline Santos & 109,0 & 14 & Blumenau & 96,4 & 64 \\
\hline João Pessoa & 108,5 & 15 & Cascavel & 96,2 & 65 \\
\hline Florianópolis & 108,3 & 16 & Taubaté & 95,8 & 66 \\
\hline Natal & 107,6 & 17 & Cubatão & 95,7 & 67 \\
\hline Petrópolis & 107,0 & 18 & Mossoró & 95,7 & 68 \\
\hline São Luís & 106,7 & 19 & Nova Friburgo & 95,2 & 69 \\
\hline Juiz de Fora & 106,1 & 20 & Montes Claros & 95,1 & 70 \\
\hline Sorocaba & 105,8 & 21 & Limeira & 95,1 & 71 \\
\hline Ribeirão Preto & 105,6 & 22 & Itajaí & 95,0 & 72 \\
\hline Teresina & 105,4 & 23 & Betim & 94,9 & 73 \\
\hline Imperatriz & 104,7 & 24 & C. do Itapemirim & 94,7 & 74 \\
\hline Guarulhos & 104,6 & 25 & Rio Grande & 94,7 & 75 \\
\hline São Caetano do Sul & 104,6 & 26 & Novo Hamburgo & 94,7 & 76 \\
\hline Cuiabá & 104,4 & 27 & Diadema & 94,6 & 77 \\
\hline São José dos Campos & 104,2 & 28 & Governador Valadares & 94,3 & 78 \\
\hline Presidente Prudente & 104,2 & 29 & Rio Claro & 94,3 & 79 \\
\hline São José do Rio Preto & 104,2 & 30 & Franca & 94,2 & 80 \\
\hline Aracaju & 104,2 & 31 & Vila Velha & 94,2 & 81 \\
\hline Maceió & 104,0 & 32 & Vitória da Conquista & 94,0 & 82 \\
\hline Anápolis & 103,6 & 33 & Jacareí & 93,8 & 83 \\
\hline São Bernardo do Campo & 103,5 & 34 & Ipatinga & 93,8 & 84 \\
\hline Uberaba & 103,5 & 35 & Divinópolis & 93,7 & 85 \\
\hline Belém & 103,2 & 36 & Porto Velho & 93,6 & 86 \\
\hline Manaus & 103,1 & 37 & Santa Maria & 93,4 & 87 \\
\hline Campo Grande & 102,9 & 38 & Macaé & 93,3 & 88 \\
\hline Campina Grande & 102,7 & 39 & Foz do Iguaçu & 93,1 & 89 \\
\hline Londrina & 102,4 & 40 & Canoas & 93,0 & 90 \\
\hline Bauru & 101,2 & 41 & Nova Iguaçu & 92,2 & 91 \\
\hline São José & 101,1 & 42 & Rio Branco & 92,1 & 92 \\
\hline Marília & 100,3 & 43 & Mauá & 92,0 & 93 \\
\hline Jundiaí & 100,3 & 44 & São Leopoldo & 91,8 & 94 \\
\hline Uberlândia & 100,0 & 45 & Bento Gonçalves & 91,7 & 95 \\
\hline Caxias do Sul & 99,4 & 46 & Jaboatão & 91,6 & 96 \\
\hline Moji das Cruzes & 99,4 & 47 & Taboão da Serra & 91,6 & 97 \\
\hline Barueri & 99,2 & 48 & Serra & 91,3 & 98 \\
\hline Maringá & 99,2 & 49 & Feira de Santana & 91,1 & 99 \\
\hline São Carlos & 98,7 & 50 & Criciúma & 91,0 & 100 \\
\hline
\end{tabular}

